\title{
La corregulación como sistema de control de las comunicaciones comerciales: ejemplos y limites
}

\section{Co-regulation as a Mechanism to Control Advertising: Examples and Limits}

Julio Álvarez Rubio* https://orcid.org/0000-0002-8658-1410

http://dx.doi.org/10.21503/lex.v17i23.1668

* Profesor de Derecho Mercantil. Director Académico de la Cátedra Euroamericana de Protección Jurídica de los Consumidores. Universidad de Cantabria, España.

Correo electrónico: julio.alvarez@unican.es

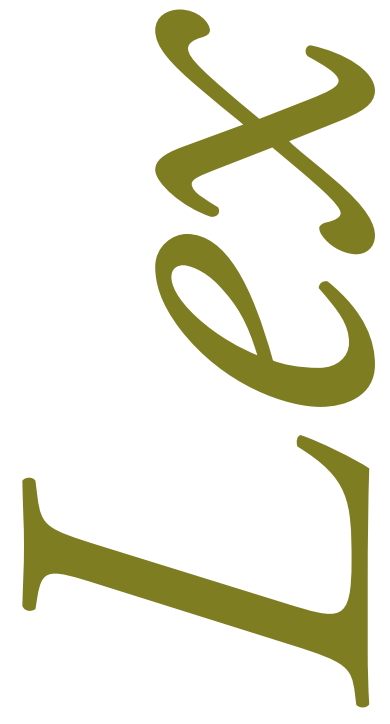
(c) (C) Los autores. Artículo publicado por la Revista Lex de la Facultad de Derecho y Ciencias Políticas de la Universidad Alas Comercial-Compartir Igual 4.0 Internacional.(http://creativecommons.org/licenses/by-nc-sa/4.0/), que permite el uso no comercial, distribución y reproducción en cualquier medio, siempre que la obra original sea debidamente citada. 


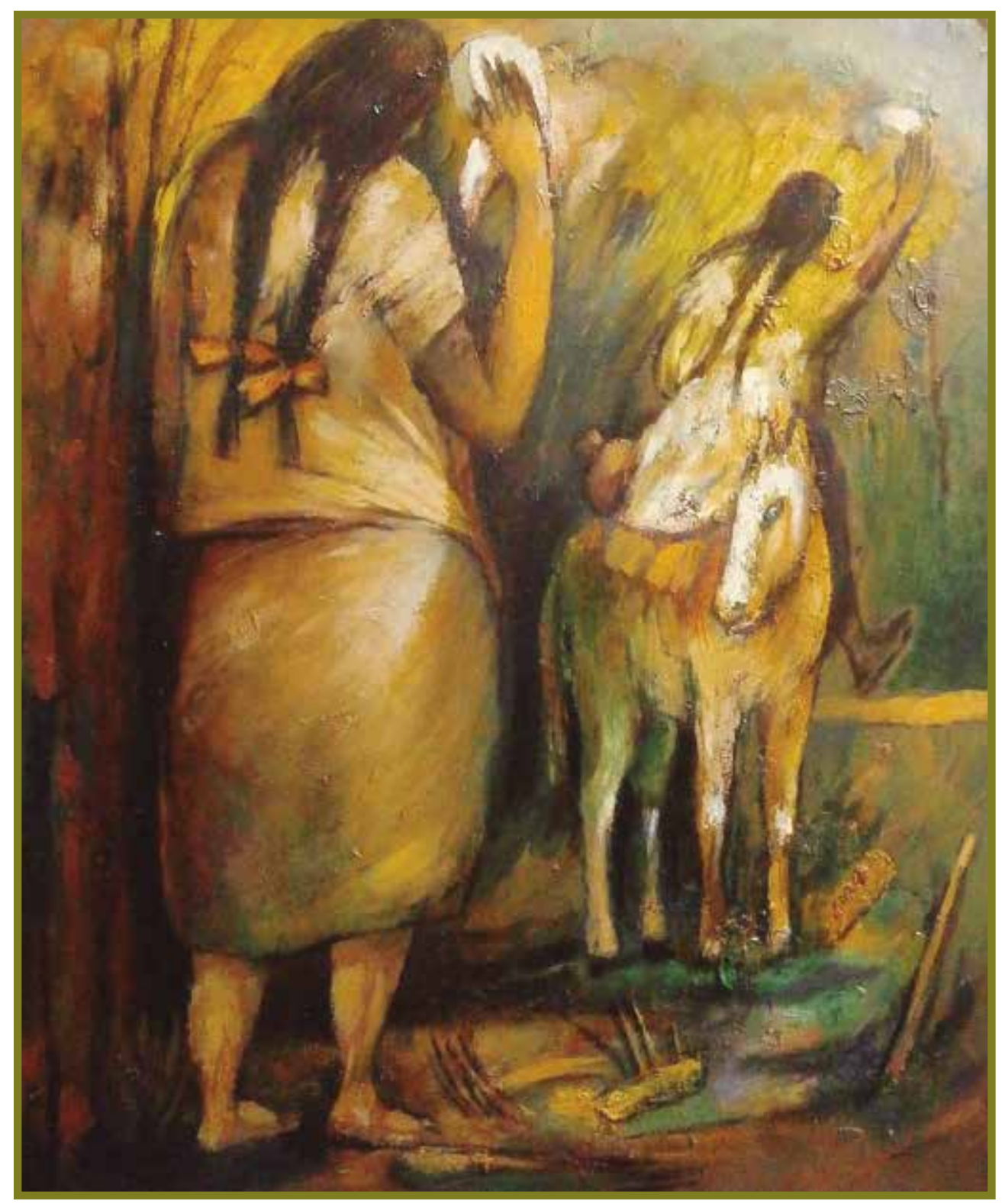

Adiós. Óleo 44 x 37 cm.

Agustín Aquino Mejías (pintor peruano). 


\section{RESUMEN}

El trabajo trata sobre la pujanza en Espańa de la corregulación como sistema de prevención y resolución de conflictos en el ámbito publicitario. Se analizan varios supuestos que confirman el éxito de semejante fórmula en diferentes ámbitos y, al mismo tiempo, se observa cómo, en algunos sectores donde el bien jurídico protegido es distinto del mero interés económico de los afectados, resulta conveniente limitar el alcance de la corregulación. A este respecto, se estudia el control de las comunicaciones comerciales dirigidas al público menor de edad en el ámbito de la alimentación, como ejemplo paradigmático de cómo la protección de la salud y la prevención de la obesidad infantil han de exigir una decidida acción legal.

Palabras clave: corregulación, publicidad, código PAOS, alimentación infantil, obesidad, consumidor, menor de edad.

\section{ABSTRACT}

This paper analyzes recent success of co-regulation in Spain as a system to prevent and solve conflicts on advertising. Some specific examples are analysed proving the success of the formula on different fields, and at the same time, showing the convenience of limiting the co-regulation scope where the economic interest is not the only interest protected. On this regard, the control of the commercial communication addressed to minor audience on the field of food and nutrition is studied as a paradigmatic example on how the health protection and the infant obesity prevention demand firm legal actions.

Key words: co-regulation, advertising, PAOS code, children's nutrition, infant obesity, consumer, minor. 


\section{LA EXPANSIÓN DE LOS SISTEMAS DE CORREGULACIÓN EN EL ÁMBITO DEL CONTROL DE LAS COMUNICACIONES COMERCIALES}

Desde hace algunos años, la autorregulación atraviesa una fase en la que, una vez superado el mero fomento, y de la mano de diferentes convenios suscritos ad hoc con la Administración y de la existencia de disposiciones legales que atribuyen efectividad práctica a las resoluciones del órgano de resolución de conflictos de la Asociación para la Autorregulación de la Comunicación Comercial en Espańa (en adelante "Autocontrol"), se podría hablar ya de corregulación.

La corregulación, como su propio nombre indica, implica la colaboración de la Administración con los sectores empresariales o profesionales interesados, sobre la base de disposiciones legales, administrativas o convencionales que dan soporte a un sistema que combina la experiencia práctica de la industria con el establecimiento de mecanismos de control y cumplimiento. ${ }^{1}$ Algún autor la define como:

El conjunto de procesos, mecanismos e instrumentos puestos en marcha por las administraciones públicas competentes y otros agentes del sector, en orden de establecer e implementar un marco de actuación adecuado a la normativa, equidistante entre los intereses de la industria y de los ciudadanos, y que se traduzca en prácticas concretas y efectivas, de tal forma que todos los agentes implicados sean corresponsables de su correcto funcionamiento. ${ }^{2}$

1 En palabras de Mercedes Muñoz Saldaña y Victorino Gómez-Iglesias Rosón, "El protagonismo de la autorregulación y de la corregulación en el nuevo mercado audiovisual digital”, Trípodos, 32 (2013): 85, la corregulación "consiste en un proceso que se apoya en el marco legal, pero que va más allá y que necesariamente debe ser pilotado por una autoridad situada al margen del ámbito en el que se aplica, pero con la obligación de implicar a todas las partes afectadas". Por su parte, el Dictamen del Comité Económico y Social Europeo sobre el tema "Autorregulación y corregulación en el marco legislativo de la Unión Europea" (2015/C 291/05), señala que "la corregulación se entiende, por lo general, como una forma de regulación de las partes interesadas (stakeholders) promovida, orientada, dirigida o controlada por una tercera entidad, ya sea un organismo oficial o una entidad reguladora independiente, que usualmente dispone de competencias de supervisión y control y, en algunos casos, de la facultad de imponer sanciones".

2 Mercedes Muñoz Saldaña y Borja Mora-Figueroa Monfort, "La corregulación: nuevos compromisos y nuevos métodos para la protección del menor de los contenidos televisivos. El caso holandés", en La ética y el derecho de la información en los tiempos del postperiodismo, ed. por Fundación COSO de la Comunidad Valenciana para el Desarrollo de la Comunicación y la Sociedad, (Valencia, 2007), 427. 
También la UE contempla este mecanismo entre sus objetivos estratégicos. Así, en su punto 18, la Decisión del Parlamento Europeo sobre la celebración del Acuerdo interinstitucional "Legislar mejor" entre el Parlamento Europeo, el Consejo y la Comisión (2003/2131(ACI), define la corregulación como "el mecanismo por el que un acto legislativo comunitario habilita para la realización de los objetivos definidos por la autoridad legislativa a las partes interesadas reconocidas en el ámbito de que se trate (en particular, los agentes económicos, los interlocutores sociales, las organizaciones no gubernamentales o las asociaciones)", considerando que solo podrá utilizarse este sistema "sobre la base de criterios definidos en el acto legislativo para garantizar la adaptación de la legislación a los problemas y a los sectores de que se trate, reducir el trabajo legislativo concentrándose en los aspectos esenciales y aprovechar la experiencia de las partes interesadas". Este esquema, que bien pudiera extrapolarse, por analogía, al resto de ámbitos territoriales en los que se desarrollan mecanismos de corregulación, culmina (punto 21 del Acuerdo) con la exigencia de que el acto legislativo sobre el que se asiente el sistema indique el alcance concreto del mismo, definiendo "las medidas pertinentes para el seguimiento de la aplicación, en caso de incumplimiento por una o varias de las partes implicadas, o de fracaso del acuerdo".

En concreto, los convenios de corregulación que "Autocontrol” tiene suscritos con la Administración despliegan sus efectos de acuerdo con tres esquemas diferentes:

- Códigos de conducta sectoriales que se acuerdan en ausencia de normas legales, encargándose "Autocontrol" de la aplicación y seguimiento de los mismos. A estos efectos se constituyen comisiones tripartitas (“Autocontrol”, Industria y Administración). Ejemplo de esta experiencia de corregulación pueden ser, entre otros, el Código de buenas prácticas para el uso de argumentos ambientales en la publicidad comercial, consecuencia del convenio suscrito con el Ministerio de Medio Ambiente y Medio Rural y Marino y Empresas del sector energético y automovilístico en 2009, el Convenio con la DGOJ y SETSI - actualmente CNMC- (2012, modificado en 2013) por el que se establece el Código de conducta sobre comunicaciones comerciales de las actividades de juego y, de forma especialmente relevante, por los intereses que trata de proteger, el Código PAOS, Código de Corregulación de la publicidad de alimentos y bebidas dirigida a menores, prevención de la obesidad y salud, en virtud de convenio suscrito con FIAB-Ministerio Sanidad, Política Social e Igualdad (2005, modificado en 2013).

- Labor de control e información por parte de "Autocontrol" de la regulación legal existente. Para ello se constituirán comisiones mixtas de seguimiento. Ejemplos de este formato pueden ser el Acuerdo de "Autocontrol" con la Secretaría de Estado de Telecomunicaciones y para la Sociedad de la Información (SETSI), según Ley 25/1994, para el fomento de la autorregulación televisiva (diciembre 2003), que establece una 
Comisión de Seguimiento SETSI-Autocontrol, la cual fija criterios, analiza, evalúa y supervisa el adecuado funcionamiento del programa; también el Acuerdo de colaboración para el fomento de la autorregulación de la actividad publicitaria con la Agencia Española de Seguridad Alimentaria y Nutrición (AESAN), actual AECOSAN, en 2008, con objeto, entre otros asuntos, de vigilar el cumplimiento del Reglamento (CE) $\mathrm{n}^{\circ} .1924 / 2006$ relativo a las declaraciones nutricionales y de propiedades saludables en los alimentos, constituyéndose una comisión de seguimiento del convenio entre las instituciones firmantes del mismo. También, como se analizará más adelante, son muy importantes las experiencias de corregulación habidas en ámbitos como la publicidad de productos financieros o de medicamentos.

- Adopción de códigos sectoriales y guías de cumplimiento que complementan y desarrollan las normas legales existentes, encargándose "Autocontrol" de vigilar la correcta aplicación de los mismos. Claro ejemplo de este sistema es el Acuerdo de colaboración suscrito entre "Autocontrol" y la Agencia Española de Protección de Datos (2013), con el objeto de establecer un mecanismo de seguimiento y control de la correcta utilización de cookies en los dispositivos terminales de los usuarios que permita detectar, corregir y, en su caso, suprimir aquellas prácticas que no se adecúen a las obligaciones legales aplicables; asimismo, el más reciente Acuerdo sobre la Autorregulación de la Publicidad de Juguetes, suscrito por "Autocontrol" con la Asociación Española de Fabricantes de Juguetes (AEFJ), y la Agencia Española de Consumo, Seguridad Alimentaria y Nutrición (AECOSAN) en diciembre de 2015.

Las experiencias, en definitiva, son abundantes y aumentan a cada momento, como prueba el Acuerdo para el fomento de la corregulación sobre las comunicaciones comerciales en televisión suscrito entre "Autocontrol" y la Comisión Nacional de los Mercados y la Competencia $(\mathrm{CNMC})$.

De la trascendencia práctica de estos distintos acuerdos y de la incidencia que los mismos han tenido en sectores tradicionalmente reacios a la asunción de sistemas de autodotación de normas y resolución alternativa de disputas, da buena cuenta la regulación adoptada en un sector tan controvertido, en las últimas fechas y a raíz de la severa crisis económica sufrida por el país, como el de la comercialización de productos financieros. Así, la Circular 6/2010, de 28 de setiembre, del Banco de Espańa, a entidades de crédito y entidades de pago, sobre publicidad de los servicios y productos bancarios, en su norma 3.2, se pronuncia en el siguiente sentido:

Sin perjuicio de la obligación de contar con una política de comunicación comercial (...) se presumirá que cuentan con procedimientos y controles internos adecuados para cumplir con lo exigido en el primer párrafo del artículo 4.3 de la Orden EHA/1718/2010, de 11 de 
junio, aquellas entidades de crédito que, para el conjunto de su actividad publicitaria, estén asociadas a sistemas de autorregulación publicitaria en Espańa que se ajusten a lo dispuesto en el artículo 37.4 de la Ley 3/1991, de 10 de enero, de Competencia Desleal, cuenten con medidas individuales o colectivas de autocontrol previo de los contenidos publicitarios, y cuyos códigos de conducta acojan el cumplimiento de los principios generales recogidos en el anejo.

Y, de forma complementaria a lo apuntado, la norma 4.2, en caso de requerimiento de cese o rectificación de la publicidad bancaria, establece lo siguiente:

La entidad deberá, en los dos días hábiles siguientes a su recepción, bien comunicar el cumplimiento del requerimiento, o bien objetarlo, alegando las razones que a su derecho convengan. En caso de que entre dichas alegaciones se indique que el mensaje publicitario cuenta con un informe de consulta previa positivo emitido por un sistema de autorregulación publicitaria que cumpla con lo dispuesto en el apartado 2 de la norma tercera, el Banco de España deberá oír, antes de dar eficacia al mencionado requerimiento, al órgano de control del correspondiente sistema de autorregulación por un plazo mínimo de tres días hábiles. Una vez cumplidos dichos trámites, el Banco de España confirmará o modificará su requerimiento en los tres días hábiles siguientes, requerimiento que deberá cumplirse de inmediato, sin perjuicio de la posibilidad del recurso administrativo que pueda caber contra el mismo.

En última instancia, la norma declara, en un precepto de singular trascendencia, que "en caso de actuación administrativa realizada en el marco de un expediente sancionador, se entenderá que la entidad actuó de buena fe si se hubiese sujetado a dicho informe de consulta previa positivo". Concluyendo, de acuerdo con las normas transcritas y tras la homologación de "Autocontrol" por el Banco de Espańa como organismo de autorregulación que cumple con lo exigido por la Orden EHA 1718/2010 y la Circular 6/2010, el Banco de Espańa presumirá buena fe a las campañas publicitarias que acrediten haber recibido copy advice positivo (dictamen previo favorable emitido a instancia del anunciante por el gabinete técnico de "Autocontrol"), lo que, sin duda, es un ejemplo evidente del respaldo legal con que cuenta el sistema en un ámbito tan complejo como el financiero.

En idéntico sentido se manifiesta la Ley 13/2011, de 27 de mayo, de regulación del juego, la cual no solo reitera la exigencia de consulta previa en caso de requerimiento de cese y la presunción de buena fe comentada en su Art. 7.4 sino que, además, en su Art. 24.5, establece:

Los sistemas de autorregulación se dotarán de órganos independientes de control para asegurar el cumplimiento eficaz de los compromisos asumidos por las empresas adheridas. Sus códigos de conducta podrán incluir, entre otras, medidas individuales o colectivas de autocontrol previo de los contenidos publicitarios y deberán establecer sistemas eficaces de resolución extrajudicial de reclamaciones que cumplan los requisitos establecidos en la normativa comunitaria y, como tales, sean notificados a la Comisión Europea, de conformidad con lo 
previsto en la Resolución del Consejo de 25 de mayo de 2000 relativo a la red comunitaria de órganos nacionales de solución extrajudicial de litigios en materia de consumo o cualquier disposición equivalente.

Resulta evidente, de acuerdo con lo expuesto, que la Administración, en los últimos tiempos, apoya de forma decidida la firma de acuerdos de corregulación que, debidamente combinados con instrumentos de autorregulación, contribuyan a resolver de forma particularmente efectiva los problemas de determinados sectores, haciendo especial hincapié en la necesidad de proteger los intereses de los consumidores a través de la articulación de tales mecanismos, si bien, como se comprobará a continuación, existen determinados ámbitos que, por su especial "sensibilidad", merecerían una atención legal más contundente y un consiguiente menor margen a la corregulación.

Obviamente, la Administración exige el cumplimiento de una serie de condiciones para prestar apoyo a los sistemas diseñados, demandando la racionalidad, publicidad y transparencia de las normas deontológicas adoptadas, la participación en su elaboración de asociaciones de consumidores, el respeto a las normas de defensa de la competencia ${ }^{3}$ y a la tutela judicial

3 En este sentido, hay que destacar que el sistema de autocontrol de la publicidad en España ha solventado con éxito los diferentes procedimientos que, relacionados con la defensa de la competencia y provocados por la interposición de alguna denuncia, han cuestionado su respeto a las normas reguladores de la competencia en los últimos tiempos. Así, una denuncia presentada por AUSBANC por supuestas prácticas colusorias impulsadas por "Autocontrol" fue archivada por la Dirección General de Defensa de la Competencia e 14 de julio de 2007. Esta resolución de archivo fue, tras el recurso interpuesto por AUSBANC, posteriormente ratificada por el Consejo de la CNC, el cual avala la legalidad de la actuación del Jurado señalando que "Es cierto que se pueden denunciar ante el Jurado campańas publicitarias de anunciantes no socios de "Autocontrol", pero está en manos de este tercero no aceptar la intervención del Jurado de Autocontrol manifestándose en este sentido en la contestación a la denuncia. Por tanto, las resoluciones del Jurado solo vinculan a terceros no socios de "Autocontrol" si estos así lo desean. También es cierto que el Jurado de la Publicidad de Autocontrol puede aplicar códigos de conducta aprobados por terceros, que voluntariamente ha decidido encomendarle el control de cumplimiento de su código de conducta publicitaria, hecho este (que sea un órgano externo, técnicamente cualificado y funcionalmente independiente) que ha sido valorado muy positivamente por el TDC en el expediente de autorización de uno de esos Códigos, el Código de la Federación Española de Bebidas Espirituosas (FEBE). Y, en último término, las resoluciones del Jurado son recurribles ante la jurisdicción”; asimismo, y en relación con el copy advice, entiende que "este instrumento no plantea problemas de competencia dado su carácter voluntario, confidencial y no vinculante para el responsable del proyecto de campaña, que además es el único que puede pedir dicho informe. Por tanto, si está en manos del responsable del anuncio no emitido pedir a "Autocontrol" la emisión de un informe jurídico, y seguir o no su parecer, difícilmente se puede calificar tal instrumento como un mecanismo de control de la estrategia publicitaria de las empresas, apto para facilitar la colusión entre competidores en el sentido de los Arts. 81.1 del Tratado de la Comunidad Europea y/o 1.1 Ley de Defensa de la Competencia. Pero es que además este tipo de informes jurídicos previos a la difusión del anuncio publicitario es expresamente deseado por el Legislador, al menos, en el ámbito de la publicidad dirigida a la mujer (Art. 13.4 de la Ley Orgánica 1/2004 de medidas de protección integral contra la violencia de género)"; por último, en relación con el posible efecto restrictivo de la competencia de los códigos de conducta, el Consejo disiente del parecer del Servicio de Defensa de la Competencia, al no considerar "que las normas de los Códigos de conducta de Autocontrol objetadas por el Servicio por restrictivas de la competencia (aunque exceptuadas conforme al Art. 81.3 TCE) caigan bajo el ámbito de aplicación de la prohibición de acuerdos colusorios de los Arts. 81.1 TCE y 1.1 LDC, porque tras su examen entiende que no son normas de conducta que impidan o limiten la libertad publicitaria de las empresas adheridas a los citados Códigos de Autocontrol más allá de lo que ya está impedida o limitada por la propia normativa 
efectiva, el establecimiento de jurados independientes que se encarguen de aplicar los códigos cumpliendo con los requisitos de funcionamiento y notificación exigidos por la UE, la incorporación de mecanismos de dictamen previo y monitoring e, incluso, la adhesión significativa de parte de la industria implicada. ${ }^{4}$

Además, el hecho de contar con un respaldo legal específico, confiere en ocasiones un plus de efectividad al propio sistema, como se evidencia de la mano del Art. 5.2 de la Ley de Competencia Desleal, que establece que "Cuando el empresario o profesional indique en una práctica comercial que está vinculado a un código de conducta, el incumplimiento de los compromisos asumidos en dicho código, se considera desleal, siempre que el compromiso sea firme y pueda ser verificado, y, en su contexto fáctico, esta conducta sea susceptible de distorsionar de manera significativa el comportamiento económico de sus destinatarios”. Esta calificación expresa de tal práctica como acto de competencia desleal refuerza extraordinariamente la vigencia de los sistemas de autocontrol existentes, pues los perjudicados por la eventual infracción, al margen de recurrir a los procedimientos internos de coerción de las respectivas organizaciones para compeler al cumplimiento de los códigos, siempre podrán invocar las acciones judiciales de cesación o rectificación que se derivan de la deslealtad concurrencial cometida, sin perjuicio de la necesidad de comunicar antes el hecho a la institución afectada, de forma que esta pueda instar con carácter previo el cumplimiento requerido, para lo cual se concede un plazo de quince días (Art. 39 LCD). Lo cierto es que la tipificación como desleal, por engañosa, del hecho de utilizar como arma publicitaria la adhesión a un código que luego se incumple supone, indudablemente, un freno para aquellos empresarios que pretendan realizar un uso fraudulento del sistema confiando en la posible tibieza de los mecanismos de control internos del mismo.

vigente, ni tampoco aprecia el Consejo que ambos Códigos de conducta de Autocontrol contengan normas que tengan por objeto limitar la competencia".

Por otro lado, y en relación con la posible incidencia negativa en el ámbito concurrencial del control previo obligatorio y vinculante de los anuncios por el Gabinete Técnico de Autocontrol que se pretendía en el Código de Autorregulación Publicitaria aprobado por la Federación Española de Bebidas Espirituosas (FEBE), la Sección Sexta de la Sala de lo Contencioso Administrativo de la Audiencia Nacional, en la sentencia de 16 de junio de 2006, se muestra tajante, al señalar que "la restricción a la política publicitaria o comercial de las empresa no nace del sometimiento al dictamen previo en materia de publicidad, que es un simple medio de control, sino de la sujeción al Código de Autorregulación Publicitaria autorizado (...) En rigor las limitaciones a la política publicitaria de las empresas asociadas en FEBE son las establecidas por la Ley, y desde su aprobación por el TDC, en el Código de Autorregulación Publicitaria (...) El Acuerdo al que se refiere este recurso [de sometimiento de los anuncios al control previo por parte del Gabinete Técnico de Autocontrol], como se ha repetido, es instrumental y no sustancial, de manera que no añade nuevas restricciones, sino garantiza la aplicación de las existentes".

4 A este respecto, conviene destacar que "Autocontrol" ha acreditado el cumplimiento de las condiciones demandadas, a tales efectos, por el Art. 37 de la Ley de Competencia Desleal, formando parte, tras la notificación realizada por la Administración a la Comisión Europea, de la Red europea de órganos de resolución extrajudicial de litigios con los consumidores (Red EJE). 
En definitiva, de lo que no cabe duda alguna es de que la irrupción de los mecanismos de auto y corregulación, sin perjuicio, lógicamente, de las competencias de la Administración y de las limitaciones que a continuación se evidenciarán, ha supuesto un punto de inflexión en materia de resolución alternativa de conflictos mediante jurados ad hoc y sistemas de autodotación de normas, relativizando cada vez más la importancia de las soluciones legislativas tradicionales y creando nuevas y complejas estructuras que suponen un antes y un después en la ordenación de la actividad de sectores empresariales y profesionales de indudable relevancia. ${ }^{5}$

\section{LÍMITES DE LA CORREGULACIÓN EN DETERMINADOS ÁMBITOS SECTORIALES: LA SALUD DE MENOR DE EDAD COMO BIEN JURÍDICO PROTEGIDO}

El control de la publicidad de alimentos o de campañas que hagan referencia, directa o indirecta, a hábitos alimenticios resulta fundamental en la sociedad actual, donde una buena parte de las patologías infantiles tienen relación con la actitud que mantienen niños y adolescentes frente a la alimentación. Por un lado, la obesidad infantil, que en los últimos tiempos está alcanzando proporciones epidémicas, ${ }^{6}$ especialmente en algunos países, y, por

5 Eugenia Fernández Fernández, "Mecanismos de protección del consumidor instaurados por la propia empresa”, en Derecho de los consumidores y usuarios, tomo II, $3^{\text {a }}$ edición, ed. por Alicia de León Arce (Valencia: Ediciones Tirant lo Blanch, 2016), 2480, realiza esta acertada reflexión en relación con el fenómeno analizado: "Se ha afirmado por un sector de la doctrina que el creciente recurso a instrumentos de autorregulación está suponiendo un cambio de paradigma en el sistema de fuentes, de la crisis del positivismo y la irrupción del postpositivismo, de un nuevo modelo de creación normativa o de un desbordamiento en el sistema de fuentes. Expresiones todas ellas referidas a una nueva realidad en la que el sistema tradicional de las fuentes del derecho se ha visto notablemente matizado. Del modelo clásico en el que la creación de las normas se atribuye de forma monopolística al poder legislativo nos encontramos en tránsito a un modelo de pluralidad de centros de producción normativa, de la hegemonía del Estado (entendido en sentido amplio) se ha transitado a un sistema en el que los propios sectores se autorregulan, de un modelo de hard law (norma vinculante creada por las instancias legislativas del Estado) se ha ido dando paulatina cabida a instrumentos de soft law (normas no vinculantes creadas por los propios sectores implicados). Las razones por las que se está produciendo ese cambio son diversas pero la más poderosa probablemente la constituya la propia insuficiencia del derecho "tradicional" para dar respuestas en una realidad social y económica muy cambiante de creciente complejidad que reclama instrumentos más ágiles, flexibles y adaptables a las nuevas circunstancias. Se trata de una verdadera trashumancia desde las rígidas estructuras jurídicas tradicionales a los campos de la autorregulación, más apropiados a los nuevos entornos sociales y económicos. En ocasiones la generación de esas pautas de autorregulación se produce de forma espontánea por los propios sectores implicados y en otras es el propio legislador nacional quien, consciente de las bondades del nuevo enfoque, hace un llamamiento a la autonormación renunciando de alguna forma a ocupar ese espacio mediante la aprobación de normas en el sentido tradicional del término y confiriendo, por el contrario, el protagonismo al grupo. Se llama a la autorregulación para evitar la regulación en un proceso de huida de las instituciones normativas tradicionales".

6 Un reciente informe de la Organización Mundial de la Salud señala que hay más de 42 millones de menores de cinco ańos con sobrepeso. La OMS destaca que la obesidad infantil es uno de los problemas más graves del siglo XXI en cuanto a salud pública, comentando que los nińos afectados por la patología tienen riesgo de padecer diabetes y enfermedades cardiovasculares a edades más tempranas, pudiendo tales afecciones derivar en muerte prematura y discapacidad. Informe de la Comisión para acabar con la obesidad infantil, editado por Organización Mundial de la Salud (2016), acceso el 8 de febrero de 2019

https://apps.who.int/iris/bitstream/handle/10665/206450/9789243510064_spa.pdf;jsessionid=15173519106D05FF629C5CC37CFC8EFF? sequence $=1$ 
otro, enfermedades como la anorexia o la bulimia, de alto impacto entre la población infantil, demandan una regulación completa y efectiva que ponga coto a prácticas irresponsables que pueden suponer un serio riesgo para la salud de niños y jóvenes.

Así, la Ley General de Comunicación Audiovisual comienza advirtiendo que "en horario de protección al menor, los prestadores del servicio de comunicación audiovisual no podrán insertar comunicaciones comerciales que promuevan el culto al cuerpo y el rechazo a la autoimagen, tales como productos adelgazantes, intervenciones quirúrgicas o tratamientos de estética, que apelen al rechazo social por la condición física, o al éxito debido a factores de peso o estética" (Art. 7.2, último párrafo). ¡Este precepto resulta fundamental, por mucho que su ámbito de aplicación resulte restringido a las emisiones televisivas y radiofónicas, a efectos de evitar campañas publicitarias del tipo de la desarrollada por Zazzle en 2011, en la que promocionaba una camiseta dirigida a un público infantil con la leyenda "nothing tastes as good as skinny feels?'. Una vez más fue el organismo autorregulador el que hubo de poner coto a la campaña referida, pronunciándose el organismo británico de autorregulación, la Advertising Standards Autority, de forma contundente:

We considered an ad that promoted a children's T-shirt that carried the slogan "NOTHING TASTES AS GOOD AS SKINNY FEELS!" implied being underweight was desirable and that it might therefore encourage children to develop an unhealthy body image and an unhealthy relationship with food. Because we considered the ad could condone or encourage an unsafe practice or result in physical, mental or moral harm to children, we concluded that it was irresponsible. The ad breached CAP Code (Edition 12) rules 1.3 (Social responsibility), 4.5 (Harm and offence) and 5.1 (Children).

La resolución terminaba exhortando a Zazzle en términos muy claros:

The ad must not appear again in its current form. We told Zazzle to ensure future ads were not irresponsible and, particularly where they were addressed to or depicted children, did not contain anything that was likely to condone or encourage an unsafe practice or to result in their physical, mental or moral harm. ${ }^{7}$

Resulta evidente que una comunicación comercial como la comentada puede producir un daño cierto a la salud de niños y adolescentes que se encuentran influenciados por el "culto al cuerpo" vigente en la sociedad actual y que pueden tomar la leyenda publicitaria al pie de la letra, desarrollando una relación perversa con la comida y, consecuentemente, hábitos alimenticios nocivos. Resulta, en consecuencia, deseable que tales riesgos se eviten a partir de una regulación legal efectiva.

ASA Adjudication on Zazzle Inc, acceso el 1 de febrero de 2019

http://www.asa.org.uk/Rulings/Adjudications/2011/8/Zazzle-Inc/SHP_ADJ_155932.aspx 
Sin duda habría que citar el Real Decreto 1907/1996, de 2 de agosto, sobre publicidad y promoción comercial de productos, actividades o servicios con pretendida finalidad sanitaria, el cual, a pesar de no contar con referencias específicas relativas a la publicidad de los "productos milagro" que, eventualmente, pudiera estar dirigida a menores, resulta esencial de cara a evitar posibles riesgos en este singular ámbito comercial. Asimismo, es clave el Reglamento (CE) no 1924/2006 del Parlamento Europeo y del Consejo, de 20 de diciembre de 2006, relativo a las declaraciones nutricionales y de propiedades saludables en los alimentos, y sus posteriores actos modificativos. Esta norma comunitaria, en su Art. 4, al regular la necesidad de establecer los perfiles nutricionales específicos y las condiciones, incluidas las exenciones, que deberán respetarse para la utilización de declaraciones nutricionales y de propiedades saludables de los alimentos o de determinadas categorías de alimentos, especifica que habrá de tenerse en cuenta, a tales fines, la función e importancia de los alimentos en la dieta de la población en general o, en su caso, de determinados grupos sometidos a riesgo, incluidos los nińos, en lo que es un claro reconocimiento de la importancia que reviste este sector poblacional de cara a su protección efectiva.

No obstante, la norma que más se refiere al ámbito concreto de la publicidad infantil, es la Ley 17/2011, de 5 de julio, de seguridad alimentaria y nutrición, la cual, en varios de sus preceptos, evidencia la concreta relevancia de niños y adolescentes como grupo merecedor de una especial protección. Así, en su Art. 40.7, la Ley establece:

Las escuelas infantiles y los centros escolares serán espacios protegidos de la publicidad. Las campañas de promoción alimentaria, educación nutricional o promoción del deporte o actividad física en los centros así como el patrocinio de equipos y eventos deportivos en el ámbito académico deberán ser previamente autorizados por las autoridades educativas competentes, de acuerdo con los criterios establecidos por las autoridades sanitarias que tengan por objetivo promover hábitos nutricionales y deportivos saludables y prevenir la obesidad.

Obsérvese que, al estilo de lo que sucedía antiguamente con la publicidad de medicamentos dirigida al público en general, el Estado se reserva la autorización previa de la misma, lo que evidencia, una vez más, la importancia que se atribuye al tema de la alimentación infantil por parte del legislador.

Asimismo, en el Art. 36.3, y dentro de la labor de implementación y desarrollo de una estrategia para fomentar una alimentación saludable y promover la práctica de actividad física, se especifica que tal estrategia priorizará las medidas dirigidas a la infancia y adolescencia. De forma coherente, el Art. 36.6 prevé, dentro de los premios NAOS, otorgados con el fin de reconocer y dar visibilidad a aquellas iniciativas consideradas ejemplares y que mejor contribuyan a la consecución de los objetivos propuestos en la referida estrategia, una categoría 
específica en el ámbito escolar, tanto para la promoción de una alimentación saludable, como para la práctica de actividad física.

También resulta destacable, a pesar de no contener disposición expresa referida al ámbito de la comunicación comercial, el Art. 37, que, al prohibir cualquier discriminación directa o indirecta (la negrita es nuestra) por razón de sobrepeso u obesidad, entendemos que podría ser perfectamente aplicable a aquellas manifestaciones publicitarias que utilizasen a personas con tales problemas físicos en situaciones ridículas o denigrantes. ${ }^{8}$ En este sentido, el punto 6 de la norma señala que "los poderes públicos adoptarán (...) medidas de intervención y fomento para la prevención y tratamiento de la obesidad, especialmente, de la obesidad infantil $(\ldots)$.

Por último, también es interesante destacar el Art. 44.3 de la ley, el cual, además de prohibir los testimoniales de profesionales sanitarios o científicos o de pacientes reales o supuestos en la publicidad o promoción, directa o indirecta, de alimentos, proscribe asimismo "la promoción del consumo de alimentos con el fin de sustituir el régimen de alimentación o nutrición comunes, especialmente en los casos de maternidad, lactancia, infancia o tercera edad”.

Sin embargo, y a pesar de todo lo expuesto, y de lo evidente que resulta la preocupación por la salud infantil frente a los riesgos a que se enfrenta, los cuales vienen propiciados, en muchos casos, por campańas publicitarias agresivas o irresponsables, resulta un tanto preocupante que la norma impulse, en este ámbito, el desarrollo de sistemas de regulación voluntaria, los cuales, a la luz de la escasa regulación existente, bien pudieran resultar sustitutivos y no complementarios, lo cual no resulta en absoluto aconsejable cuando el objetivo último es la protección de un bien jurídico como la salud de niños y adolescentes. Así, y de forma general, el Art. 45 proclama su intención de favorecer y velar por la implantación de los sistemas de autorregulación referidos, pero, de forma más concreta, si bien en clave de corregulación, el Art. 46.1 señala, para este específico sector poblacional que:

Las autoridades competentes promoverán la firma de acuerdos de corregulación con los operadores económicos y los prestadores del servicio de comunicación comercial audiovisual, para el establecimiento de códigos de conducta, que regulen las comunicaciones comerciales de alimentos y bebidas, dirigidas a la población menor de quince años, con el fin de contribuir a prevenir la obesidad y promover hábitos saludables (...).

8 Como ejemplo podría valer el del anuncio de la cadena de supermercados alemanes "Edeka", que presenta a personas obesas como seres físicamente desagradables, deprimidos y antipáticos, además de considerarlos como fracasados en cuanto a la realización de sus sueńos. "El polémico anuncio de un supermercado alemán que estigmatiza a los gordos", en República de las ideas, acceso el 30 de enero de 2019

https://www.republica.com/2017/02/26/el-polemico-anuncio-de-un-supermercado-aleman-que-estigmatiza-a-los-gordos/ 
A tales efectos establece un plazo máximo de un año para la adopción de los referidos códigos, en lo que parece una clara apuesta por este singular ADR en un ámbito tan sensible como el ahora analizado. De hecho, el propio precepto, en su número segundo, solo prevé regulación reglamentaria que garantice "la protección de la infancia y la juventud, así como los medios para hacerlas efectivas", en caso de ausencia de tales códigos, en lo que supone un claro reconocimiento del carácter fundamental y no supletorio de los mismos a los efectos comentados.

En similar sentido, el Art. 7.4 de la LGCA, establece:

La autoridad audiovisual competente promoverá entre los prestadores del servicio de comunicación audiovisual televisiva el impulso de códigos de conducta en relación con la comunicación comercial audiovisual inadecuada, que acompañe a los programas infantiles o se incluya en ellos, de alimentos y bebidas que contengan nutrientes y sustancias con un efecto nutricional o fisiológico, en particular aquellos tales como grasas, ácidos transgrasos, sal o sodio y azúcares, para los que no es recomendable una ingesta excesiva en la dieta total.

Pues bien, resultado de este más que evidente interés del legislador por promover la autorregulación en el ámbito de la publicidad infantil alimentaria es el Código de Corregulación de la publicidad de alimentos y bebidas dirigida a menores, prevención de la obesidad y salud (Código PAOS) con FIAB-Ministerio Sanidad, Política Social e Igualdad, de 2005, si bien cuenta con una importante modificación en 2012. El epígrafe III de este Código establece, como norma ética a seguir en materia de educación e información nutricional, lo siguiente:

Como regla general, los mensajes publicitarios de alimentos o bebidas no deberán promover o presentar hábitos de alimentación o modos de vida poco saludables tales como comer o beber de forma inmoderada, excesiva o compulsiva, ni deberán fomentar, aprobar o presentar de forma condescendiente hábitos de vida sedentarios. A tal efecto, la publicidad de estos productos dirigida a menores de hasta 12 años, difundida en medios audiovisuales e impresos o a menores de 15 años en Internet, no deberá mostrar el alimento o bebida promocionado en cantidades excesivas o desproporcionadas. Asimismo, cuando la publicidad presente el alimento o bebida promocionado en el contexto de una comida, deberá mostrarse acompañado de una variedad razonable de alimentos con el fin de que el mensaje publicitario fomente su consumo como parte de una dieta variada y equilibrada.

Asimismo, señala que "la publicidad de alimentos o bebidas nunca deberá minusvalorar la importancia de hábitos de vida saludables, tales como el mantenimiento de una alimentación variada, equilibrada y moderada o la realización de actividad física" y que, "en la publicidad dirigida a los menores de hasta 12 años (...), ningún producto puede presentarse como sustitutivo de ninguna de las tres comidas principales (desayuno, comida y cena)”. 
El Código muestra también su preocupación por la correcta presentación del mensaje publicitario (epígrafe IV), dada la menor experiencia y mayor credulidad e ingenuidad de los menores, señalando, explícitamente, que "la presentación publicitaria de alimentos o bebidas no deberá inducir a error a los menores de hasta 12 años difundida en medios audiovisuales e impresos o a menores de 15 años en Internet, sobre los beneficios derivados del uso del producto. Entre ellos podrían señalarse, aunque la lista no sea exhaustiva: la adquisición de fortaleza, estatus, popularidad, crecimiento, habilidad e inteligencia”. De forma específica, entiende que hay que adoptar especial cautela para no explotar abusivamente la imaginación infantil, pues la fantasía, incluyendo las animaciones y los dibujos animados, resulta idónea tanto para los niños más pequeños como para los mayores, pero ha de evitarse que la utilización publicitaria de tales elementos cree expectativas inalcanzables o explote la ingenuidad de los niños más pequeños a la hora de distinguir entre fantasía y realidad.

En relación con la información a proveer en el seno de la comunicación comercial, resulta muy interesante el epígrafe $\mathrm{V}$ de la norma, pues, como se va a comprobar, ataja de raíz los problemas que una deliberadamente confusa presentación del mensaje publicitario (aspecto que ya se ha analizado en el presente trabajo) pudiera ocasionar al público infantil:

Los menores, especialmente los menores de hasta 12 años de edad, tienen un vocabulario más limitado y unas habilidades lingüísticas menos desarrolladas que los adultos. Leen peor, cuando lo hacen, y confían más en la información presentada por medio de imágenes que por las palabras. El uso de un lenguaje simplificado aumenta significativamente la comprensión (...) La publicidad de alimentos y bebidas dirigida a menores de hasta 12 años deberá expresarse en un lenguaje comprensible para este público y de forma clara, legible y destacada. Con tal fin, si esa información adicional se ofrece a través de una sobreimpresión, se cuidará el tamaño de las indicaciones, el contraste con el fondo, así como su tiempo de permanencia en pantalla.

El Código PAOS se preocupa también de proteger al público infantil frente a técnicas de "presión de ventas" excesivamente agresivas, como evidencia lo establecido por su norma 12:

La publicidad no debe dar la impresión de que adquirir o consumir un alimento o bebida dará una mayor aceptación del niño entre sus amigos. Y al contrario, tampoco debe implicar que no adquirir o consumir un producto provocará el rechazo del niño entre sus compañeros. Los anuncios no deben sugerir que la compra y el uso del producto aportarán al usuario el prestigio, las habilidades y otras cualidades especiales de los personajes que aparecen en el anuncio. ${ }^{?}$

9 En este sentido resulta expresiva la denuncia que PROFECO, el órgano regulador mexicano, recibe de una asociación de consumidores respecto de un anuncio de cereales Kellogs, basado en una animación de su mascota, representada por un tigre, que participa en diferentes competiciones deportivas junto con niños. Los elementos criticados son que el dibujo animado pretende transferir al producto la emoción que genera el personaje en el niño y el mensaje de que, comiendo 
El epígrafe VII se dedica, de forma exhaustiva, a regular, muy restrictivamente, el uso de "testimoniales" en la publicidad dirigida a nińos, consciente de que la influencia que la aparición de un personaje "famoso", sea real o ficticio, en la publicidad puede tener en la decisión de compra final del producto promocionado es, en este sector poblacional, decisiva. La norma 14.1, aun previendo alguna excepción, se muestra tajante al respecto: "en la publicidad de alimentos o bebidas dirigida a menores de hasta 12 años no participarán ni aparecerán personajes especialmente próximos a este público, tales como, por ejemplo, presentadores de programas infantiles, personajes -reales o ficticios- de películas o series de ficción, u otros".

Por último, el Código realiza también una severa regulación de las posibles prácticas de publicidad "editorial" o cuya naturaleza publicitaria resulta difícil de percibir para el público infantil (epígrafe X), restringe la publicidad comparativa (epígrafe XI) y aborda, de forma extensa, el problema de las promociones, sorteos, concursos y clubes infantiles y su posible utilización comercial (epígrafe XI).

Con todo, aun reconociendo que la norma supone un claro avance en la protección de los niños y adolescentes frente al acoso de la publicidad en el ámbito alimentario, e incluso independientemente de los eventuales problemas que la autorregulación puede generar ante eventuales incumplimientos del código, lo cierto es que se echan en falta preceptos específicos que limiten la publicidad de determinados productos por ser intrínsecamente perjudiciales para la población infantil. En efecto, si bien se ha comprobado que la norma obliga a ubicar el producto promocionado en un contexto de mesura y variedad, lo cierto es que no realiza distingo alguno respecto del producto en cuestión, sea este una fruta o una verdura, o una pieza de bollería industrial, resultando patente que ambos alimentos habrían de merecer diferente trato desde el punto de vista publicitario, especialmente cuando el anuncio va dirigido al público infantil o juvenil. No hay que olvidar que el Art. 7.4 de la LGCA hacía lógico hincapié en la necesidad de adoptar un código de autorregulación respecto de la publicidad de "alimentos y bebidas que contengan nutrientes y sustancias con un efecto nutricional o fisiológico, en particular aquellos tales como grasas, ácidos transgrasos, sal o sodio y azúcares, para los que no es recomendable una ingesta excesiva en la dieta total". Resulta por tanto curioso que la industria haya optado por una regulación "general", que no alude específicamente a la habitualmente denominada "comida basura", y que trata indiscriminadamente a productos de consumo recomendable para nińos y adolescentes como a

ese cereal, se puede convertir en un tigre, así como que el consumo del producto se vincula al triunfo y a la victoria. Asimismo, se denunciaba que dicho cereal es un procesado de harina de maíz que contiene 14 gramos de sacarosa y otros azúcares en cada porción de 30 gramos, lo que equivale a que $40 \%$ del cereal es sólo azúcar, por lo que, en definitiva, dista mucho de ser un producto saludable para el consumo infantil. En Kellogg's, denunciada en México por promover hábitos inadecuados entre los niños, acceso el 15 de enero de 2019

https://www.facua.org/es/noticia.php?Id=1969 
productos cuya composición nutricional sitúa muy lejos de los que ha de considerarse una dieta equilibrada. ${ }^{10}$

Consideramos que, de igual forma que la publicidad de determinadas sustancias perjudiciales para la salud dirigidas a adultos (publicidad y tabaco, por poner un ejemplo) se encuentra severamente restringida mediante normas de rango legal, lo mismo debiera suceder, siquiera en un contexto de autorregulación, con determinado tipo de comida cuya ingesta por parte de la población infantil se está convirtiendo en un serio problema de salud pública. Si la opción de vetar la publicidad de los referidos productos en las bandas horarias o soportes de habitual acceso infantil pudiera resultar excesiva, al menos la obligación de advertir por parte de los anunciantes de los riesgos sanitarios que el consumo frecuente o excesivo de tales alimentos o bebidas puede ocasionar para la salud de niños y adolescentes debería ser un precepto central del referido código.

A este respecto, campañas como las de Burger King, que se mofaba de la opción vegetariana con el lema "terrible ser vegetariano ¿verdad?", al anunciar una hamburguesa XXL, que no solo no resultaba nutricionalmente adecuada por su excesivo aporte calórico sino que, además, aportaba un exceso de grasas saturadas absolutamente desaconsejable, no solo no advierten de los riesgos que este tipo de comida, especialmente atractiva para los adolescentes, puede ocasionar, sino que promueven el consumo excesivo de la misma. ${ }^{11}$ De forma mucho más sutil, pero igualmente confusionista, no resulta lógico que una bolsa de cortezas de trigo, alimento que dista mucho de constituir paradigma de dieta equilibrada, ubique en su dorso una pirámide nutricional culminada con la leyenda "estilo de vida saludable", pues, si bien la lectura reposada de los consejos que acompañan a esa representación se corresponden con lo que debería ser ese estilo de vida, su mera presencia en el envase de un alimento que no es en sí mismo saludable, puede inducir a obvia confusión. ${ }^{12}$

En definitiva, entendemos que la norma se muestra tibia en relación con lo que debería ser el principal objetivo de la misma, que no es otro que evitar el consumo masivo de determinados alimentos que, por su naturaleza (no creemos que suponga riesgo alguno el consumir un número alto de manzanas o de tomates...), no resultan adecuados para nińos $\mathrm{y}$ adolescentes.

10 El Código cuenta con la adhesión de más del 95\% de la inversión publicitaria del sector, porcentaje superior a la media de adhesión del resto de códigos sectoriales.

11 Ver imagen en Vetada la campaña publicitaria de Burger King, terrible ser vegetariano ¿verdad?, acceso el 10 de febrero de 2019

http://www.directoalpaladar.com/otros/vetada-la-campana-,publicitaria-de-burger-king-terrible-ser-vegetariano-verdad,

12 Ver imagen y comentario en Juan Revenga, “¿Qué es lo que "grita” un snack desde la cúspide de la pirámide?”, en 20 minutos, acceso el 18 de enero de 2019

https://blogs.20minutos.es/el-nutricionista-de-la-general/tag/refrescos/page/2/ 


\section{CONCLUSIONES}

La autorregulación y la corregulación son instrumentos que han demostrado, en los últimos tiempos, su indudable utilidad como mecanismos que permiten a determinados sectores autodotarse de normas, en su mayor parte de naturaleza deontológica, bien de forma autónoma, bien de acuerdo con la Administración. El impulso de estos sistemas ha logrado que ciertos ámbitos económicos se sientan más implicados con la regulación de su actividad y, en consecuencia, más propensos al cumplimiento de las normas establecidas, estableciéndose en paralelo, además, mecanismos de resolución alternativa de conflictos que propician una solución más ágil y eficiente de las controversias que puedan surgir.

Uno de los campos donde, tanto a nivel español como internacional, tales sistemas han alcanzado una implantación y éxito considerable es el de la publicidad. En efecto, la proliferación de códigos de conducta generales y sectoriales con objeto de autodisciplinar la difusión de comunicaciones comerciales es un hecho en la mayoría de los países económicamente avanzados, apreciándose, asimismo, el surgimiento, ya comentado, de órganos de autocontrol que coadyuvan al prestigio del sistema.

Sin embargo, si bien en un primer momento la mayoría de estos sistemas servían de complemento a las normas legales y a los mecanismos jurisdiccionales existentes, los cuales se encontraban dispuestos a efectos de corregir eventuales fallas del sistema de autorregulación, en la actualidad se aprecia una creciente deriva, materializada en técnicas de corregulación, que propicia que las normas éticas de las que se provee la industria sustituyan, con el apoyo expreso o tácito de la Administración, a las normas legales, lo cual, en muchos casos, genera un riesgo evidente de desprotección para los consumidores y usuarios de los bienes o servicios afectados.

En este trabajo se ha evidenciado el riesgo de dejar en manos de la corregulación un sector tan sensible, desde el punto de vista social, como el de la publicidad de alimentos destinados a la población infantil, suponiendo tal hecho una cierta relajación del régimen al que debiera someterse semejante actividad, la cual, no hay que olvidarse, puede afectar no solo a los intereses económicos de los implicados sino, de forma muy sensible, a su salud y calidad de vida.

En definitiva, se deben establecer límites a las técnicas corregulatorias, especialmente en aquellos sectores en los que, como el estudiado, la confrontación entre los intereses de los lobbies empresariales y los de los usuarios afectados puede generar una cierta relajación interesada de las normas aplicables en favor de la industria; y de forma muy especial, además, cuando es la salud de los ciudadanos lo que está en juego. 


\section{REFERENCIAS}

- ASA Adjudication on Zazzle Inc. Acceso el 1 de febrero de 2019. http://www.asa.org.uk/Rulings/Adjudications/2011/8/Zazzle-Inc/SHP_ADJ_155932.aspx

- "El polémico anuncio de un supermercado alemán que estigmatiza a los gordos”. En República de las ideas. Acceso el 30 de enero de 2019.

https:/www.republica.com/2017/02/26/el-polemico-anuncio-de-un-supermercadoaleman-que-estigmatiza-a-los-gordos/

- Fernández Fernández, Eugenia. "Mecanismos de protección del consumidor instaurados por la propia empresa”. En Derecho de los consumidores y usuarios, tomo II, $3^{\text {a }}$ edición, ed. por Alicia de León Arce. Valencia: Ediciones Tirant lo Blanch, 2016.

- Informe de la Comisión para acabar con la obesidad infantil, editado por Organización Mundial de la Salud (2016). Acceso el 8 de febrero de 2019. https://apps.who.int/iris/bitstream/handle/10665/206450/9789243510064_spa. pdf;jsessionid=15173519106D05FF629C5CC37CFC8EFF?sequence $=1$

- Kellogg’s, denunciada en México por promover hábitos inadecuados entre los niños. Acceso el 15 de enero de 2019.

https://www.facua.org/es/noticia.php?Id=1969

- Muñoz Saldaña, Mercedes y Victorino Gómez-Iglesias Rosón. "El protagonismo de la autorregulación y de la corregulación en el nuevo mercado audiovisual digital”. Trípodos, 32 (2013).

- Muñoz Saldaña, Mercedes y Borja Mora-Figueroa Monfort, "La corregulación: nuevos compromisos y nuevos métodos para la protección del menor de los contenidos televisivos. El caso holandés". En La ética y el derecho de la información en los tiempos del postperiodismo, ed. por Fundación COSO de la Comunidad Valenciana para el Desarrollo de la Comunicación y la Sociedad. Valencia, 2007.

- Revenga, Juan. “¿Qué es lo que “grita” un snack desde la cúspide de la pirámide?”. En 20 minutos. Acceso el 18 de enero de 2019.

https://blogs.20minutos.es/el-nutricionista-de-la-general/tag/refrescos/page/2/ 
- Vetada la campaña publicitaria de Burger King, terrible ser vegetariano ¿verdad? Acceso el 10 de febrero de 2019.

http://www.directoalpaladar.com/otros/vetada-la-campana-publicitaria-de-burger-kingterrible-ser-vegetariano-verdad

RECIBIDO: $13 / 02 / 2019$

APROBADO: 19/04/2019 